\title{
Comparison of Measurement Methods of Osmotic Adjustment in Rice Cultivars
}

\author{
R. Chandra Babu, M. Safiullah Pathan, A. Blum,** and Henry T. Nguyen
}

\section{ABSTRACT}

Osmotic adjustment $(\mathrm{OA})$ is a major component of drought resistance. Four different methods for measuring $\mathrm{OA}$ in plants are in general use, but there is no information on the comparative performance of these methods. Two similar experiments were designed to evaluate the four methods for measuring $\mathrm{OA}$ in diverse indica and japonica cultivars of rice (Oryza sativa L.) subjected to a drying cycle in large pots in the greenhouse. The four methods were: (i) derivation of $\mathrm{OA}$ from regressions of leaf relative water content $(\mathrm{RWC})$ on leaf osmotic potential (OP); (ii) estimation of OA from OP of stressed plants calculated to rehydrated state; (iii) estimation of $\mathrm{OA}$ from $\mathrm{OP}$ of stressed plants that have been rehydrated; and (iv) estimation (from data used in Method 1) of OA capacity by the sustained RWC at a given OP of -3.5 MPa. Method 1 was a priori considered as the best estimate. Under relatively mild atmospheric conditions and a slow development of water deficit (first experiment), mean $\mathrm{OA}$ over 12 cultivars was $0.89,0.51$, and 0.72 MPa by Methods 1,2 , and 3, respectively. Mean RWC at -3.5 MPa was $69.3 \%$. Significant $(P \leq 0.05)$ variation in $\mathrm{OA}$ among cultivars was observed by all methods, up to a four-fold difference in $\mathrm{OA}$ among cultivars (0.35-1.51 MPa) by Method 1. Simple correlation for $\mathrm{OA}$ across 12 cultivars with Method 1 was significantly higher for Method $3(r=0.76 ; P=0.04)$ and Method $4(r=0.87 ; P<0.01)$ than for Method $2(r=0.54 ; P=$ 0.07). OA by Method 4 was better correlated with Method 3 ( $r=$ $0.80 ; P<0.01)$ than with Method $2(r=0.67 ; P=0.02)$. The coefficient of variation $(\mathrm{CV})$ as a measure of error was greater for Method 1 (47\%) and Method $2(31 \%)$ than for Method $3(21 \%)$ or $4(24 \%)$. Both Methods 2 and 3 were less demanding on labor and plant materials than Methods 1 and 4 . The results support the use of Method 3 (the "rehydration method") as a faster and an economical replacement for Method 1.

$\mathrm{O}$ SMOTIC ADJUSTMENT is recognized as an effective component of drought resistance in several crop plants (reviewed by Morgan, 1984; Blum, 1988; Ludlow and Muchow, 1990; Kramer and Boyer, 1995). Osmotic adjustment involves the net accumulation of solutes in a cell in response to a fall in the water potential of the cell's environment. As a consequence of this net accumulation, the osmotic potential of the cell is lowered, which in turn attracts water into the cell and tends to maintain turgor pressure. Generally, OA contributes to turgor maintenance of both shoots and roots as plants experience water deficit. This allows turgor-dependent processes such as growth and stomatal activity to continue to progressively lower leaf water potential (LWP). The accumulated compatible solutes may also protect

R. Chandra Babu, M. Safiullah Pathan, Henry T. Nguyen; Plant Molecular Genetics Lab., Dep. of Plant and Soil Science, Texas Tech Univ., Lubbock, TX 79409-2122; A. Blum, The Volcani Center, ARO, P.O. Box 6, Bet Dagan 50250, Israel. This research was funded by the Rockefeller Foundation under International Program on Rice Biotechnology. This is contribution number T-4-431 of the College of Agricultural Sciences and Natural Resources, Texas Tech Univ., Lubbock, TX 79409. Received 30 March 1998. *Corresponding author (vcablm@volcani.agri.gov.il).

Published in Crop Sci. 39:150-158 (1999). specific cellular functions, irrespective of turgor (Paleg et al., 1985; Shen et al., 1997).

Substantial genotype diversity for OA was observed in wheat (Triticum aestivum L.) (Morgan, 1977; Morgan et al., 1986), sorghum (Sorghum spp.) (Blum and Sullivan, 1986; Santamaria et al., 1990; Basnayake et al., 1993; Tangpremsri et al., 1995), chickpea (Cicer arietinum L.) (Morgan et al., 1991), field pea (Pisum sativum L.) (Rodrigues-Maribona et al., 1992), black spruce [Picea mariana (Mill.) B.S.P.] (Tan and Blake, 1997), sunflower (Helianthus annuus L.) (Jamaux et al., 1997), and various turfgrasses (Qian and Fry, 1997). Osmotic adjustment occurs in rice subjected to water deficit (Cutler et al., 1980; Steponkus et al., 1982; Hsiao et al., 1984; Turner et al., 1986). The genetic range of variation for OA in rice was found to be about 0.5 to $0.6 \mathrm{MPa}$, over a limited number of cultivars (Cutler et al., 1980; Turner et al., 1986). Greater variation may be expected if a broader genetic base is examined (Lilley and Ludlow, 1996).

The comparison of OA data from different studies is hampered by differences in methodology and protocol. Different methods for the determination of OA in plants have been proposed and used (e.g., Jones and Turner, 1978; Wilson et al., 1979; Ludlow et al., 1983; Blum, 1989; Morgan, 1992). The measurement of OA should estimate the net solute accumulation in tissues in response to tissue water deficit, independently of the mere effect of solute concentration due to the water loss from the tissue. Secondly, the method should account for the pronounced effect of the rate and extent of water deficit on OA (e.g., Jones and Rawson, 1979). This is a major problem when diverse genetic materials are compared for OA, if they differ also in plant size, root traits, or any other plant factor that determines the rate of plant dehydration in the field or in a pot (e.g., Blum et al., 1997). Therefore, OA measurement requires a reasonable standardization of or normalization for plant tissue water deficit.

The various published methods for OA measurement can be classified into four procedures (see Materials and Methods for details). Briefly, the first method (Morgan, 1992, 1995) estimates OA from the linear regressions of $\mathrm{RWC}$ on OP as derived from consecutive measurements during a drought stress cycle. It partitions between active solute accumulation (i.e., OA) and the "concentration effect" on OP of water loss from the tissues. The method is comprehensive and demanding on labor and plant materials. It is here considered as the best estimate by the token of its extensive data acquisition along a drying cycle and its account for the concentration effect.

The second method (Wilson et al., 1979; Ludlow et

Abbreviations: $B$, tissue apoplastic water; LWP, leaf water potential; OA, osmotic adjustment; OP, leaf osmotic potential; Opi, initial OP after irrigation; $\mathrm{RWC}$, leaf relative water content; $\mathrm{RWC}_{100}, \mathrm{RWC}$ of well-watered plants; RWCi, initial RWC after irrigation. 
al., 1983, 1990) is relatively more simple and it estimates $\mathrm{OA}$ from the difference in $\mathrm{OP}$ at $\mathrm{RWC}_{100}$ between nonstressed and stressed plants. By this method OP at $\mathrm{RWC}_{100}$ is calculated from a point measurement of $\mathrm{OP}$ and RWC at a given level of plant water deficit, with a correction for tissue apoplastic water $(B)$.

By comparison, the third method (Turner and Jones, 1980; Blum, 1989) also estimates OA by a point measurement of the difference in $\mathrm{OP}$ at $\mathrm{RWC}_{100}$ between nonstressed and stressed plants. However, here OP at $\mathrm{RWC}_{100}$ of stressed plants is actually measured after plants or parts thereof are rehydrated to $\mathrm{RWC}_{100}$.

The fourth method is a variation of the first method employed by Morgan (1992, 1995), where the relative capacity for OA is derived from the regression of RWC on OP and estimated as the RWC at a given OP, which is at about wilting. The first and fourth methods use the same data set for different computations.

The second and third methods are relatively less demanding in terms of labor and plant materials, and they are therefore suitable for screening work. However, no attempt has ever been made to compare all four methods in one study. In view of the recent interest in measuring OA in plant breeding and molecular work, a comparative evaluation of all available methods is warranted; therefore, we conducted this study to compare the four methods using different rice cultivars.

\section{MATERIALS AND METHODS}

\section{Plant Materials and Growth Conditions}

Rice cultivars representing a wide range of germplasm from traditional upland types to improved lowland types were studied (Table 1). Seed of these cultivars was obtained from the International Rice Research Institute, Manila, Philippines. Plants were grown in the greenhouse at Texas Tech University, Lubbock, Texas, during October to December 1994 (Exp. 1) and May to July 1995 (Exp. 2). Air temperatures inside the greenhouse during the two experiment periods are represented in Fig. 1. Twelve and eight cultivars were tested in

Table 1. Initial leaf relative water content (RWCi) and initial osmotic potential (OPi) of well-watered plants (at the vegetative stage) as measured before drought stress (on the morning after the last irrigation) in 12 rice cultivars (Exp. 1).

\begin{tabular}{|c|c|c|c|}
\hline Cultivar & $\begin{array}{c}\text { Ecological/agronomic } \\
\text { type }\end{array}$ & RWCi & OPi \\
\hline & & $\%$ & MPa \\
\hline IR52561-UBN-1 $\dagger$ & indica, lowland & 99.8 & -2.02 \\
\hline IR42 & indica, lowland & 98.6 & -2.01 \\
\hline IR58821-23-B-1-2-1 $\dagger$ & indica, lowland & 98.6 & -1.90 \\
\hline Teqing & $\begin{array}{l}\text { indica, lowland from } \\
\text { China }\end{array}$ & 97.1 & -1.74 \\
\hline IR 63919-38-B-1 $\dagger$ & indica, lowland & 99.4 & -1.73 \\
\hline IR64† & indica, lowland & 99.5 & -1.71 \\
\hline IR6226-42-6-2† & indica, lowland & 97.9 & -1.68 \\
\hline Azucenat & japonica, upland & 95.5 & -1.59 \\
\hline KDML-105 & indica, lowland & 99.5 & -1.58 \\
\hline CT9993-5-10-1-M $\dagger$ & $\begin{array}{l}\text { indica, semi-upland, } \\
\text { japonica parentage }\end{array}$ & 98.9 & -1.58 \\
\hline Lemont & japonica from US & 98.3 & -1.56 \\
\hline Moroberekan & $\begin{array}{l}\text { japonica, upland from } \\
\text { Guinea }\end{array}$ & 98.0 & -1.50 \\
\hline Mean & & 98.4 & -1.72 \\
\hline LSD (0.05) & & 1.5 & 0.28 \\
\hline
\end{tabular}

$\dagger$ Also tested in Exp. 2.
Exp. 1 and Exp. 2, respectively. Plants were grown in large $(18 \mathrm{~L})$ polyvinyl pots each filled with $6 \mathrm{~kg}$ of a commercial mixture of peat moss, perlite, bark, and vermiculite (Ball "Growing-on" Mix-1, Ivy Gardens, Lubbock, TX). Two plants were established from seed in each pot. A randomized complete block design, with twelve pots per cultivar was used for the experiments. Pots were irrigated regularly with tap water and every $15 \mathrm{~d}$ with a standard nutrient solution (MiracleGro liquid fertilizer, Port Washington, NY). This potting mixture and fertilization regime have already been tested for several seasons and found to be appropriate for optimal rice growth. The last irrigation was applied (in the evening) at 54 and $40 \mathrm{~d}$ after sowing in Exp. 1 and 2, respectively. Osmotic adjustment was determined by four methods in Exp. 1 and by two methods (1 and 3) in Exp. 2.

\section{Water Relations Measurements}

The RWC, LWP, and OP were measured every alternate day at midday. The first measurement was taken in wellwatered plants on the morning (predawn) after the last irrigation and the last measurement when plants wilted. Wilting was judged as complete rolling of the youngest leaves and desiccation of older leaves (De Datta et al., 1988). At this state RWC was between 55 and $65 \%$, depending on cultivar.

On each date, RWC and OP were measured in the midsection of the same second-youngest, fully expanded leaf blade. The RWC was determined by the standard method (Barrs and Weatherley, 1962), using a 4-h rehydration period and oven drying for $24 \mathrm{~h}$ at $80^{\circ} \mathrm{C}$. For OP measurement, a sample consisting of three 1-cm-long midleaf segments was sealed in a thermocouple psychrometer cup (2-mL volume) and freeze-

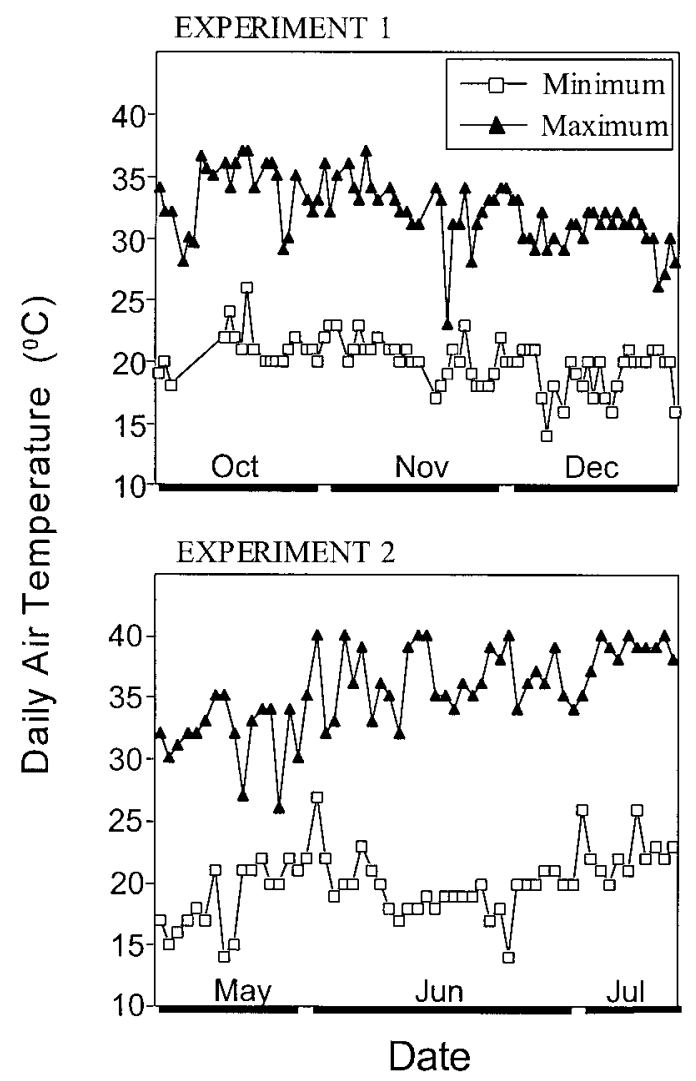

Fig. 1. Daily maximum and minimum air temperatures in the greenhouse at Lubbock, TX during Exp. 1 (October-December 1994) and Exp. 2 (May-July 1995). 
killed at $-20^{\circ} \mathrm{C}$. Prior to measurement, samples were thawed for $30 \mathrm{~min}$ at room temperature. The LWP was measured in similar leaf samples, without freezing. Potentials were measured by a commercial Peltier type thermocouple psychrometer (Model SC-10A, Decagon Devices, Inc., Pullman, WA) after a 2-h equilibration period with a cooling current for $15 \mathrm{~s}$ (Brown and Oosterhuis, 1992). This protocol has been previously tested and determined to be appropriate, as calibrated against solutions of $\mathrm{NaCl}$ of known osmotic potentials. Three replications per cultivar per sampling date were measured for all three variables.

\section{Osmotic Adjustment Determination}

Osmotic adjustment was measured and calculated in three replications per cultivar.

Method 1. Following Morgan (1992), two linear regressions were developed for all measurements taken during the drying cycle in all plants belonging to a given replication (Fig. 2; examples for two cultivars). One consisted of the regression of RWC on the measured OP (Fig. 2 solid squares) and the other of RWC on calculated OP due to a concentration effect $\left(\mathrm{OP}_{0}\right)$ (Fig. 2 open squares). The $\mathrm{OP}_{0}$ was therefore an estimate of tissue OP level ascribed to the mere loss of water at each given RWC.

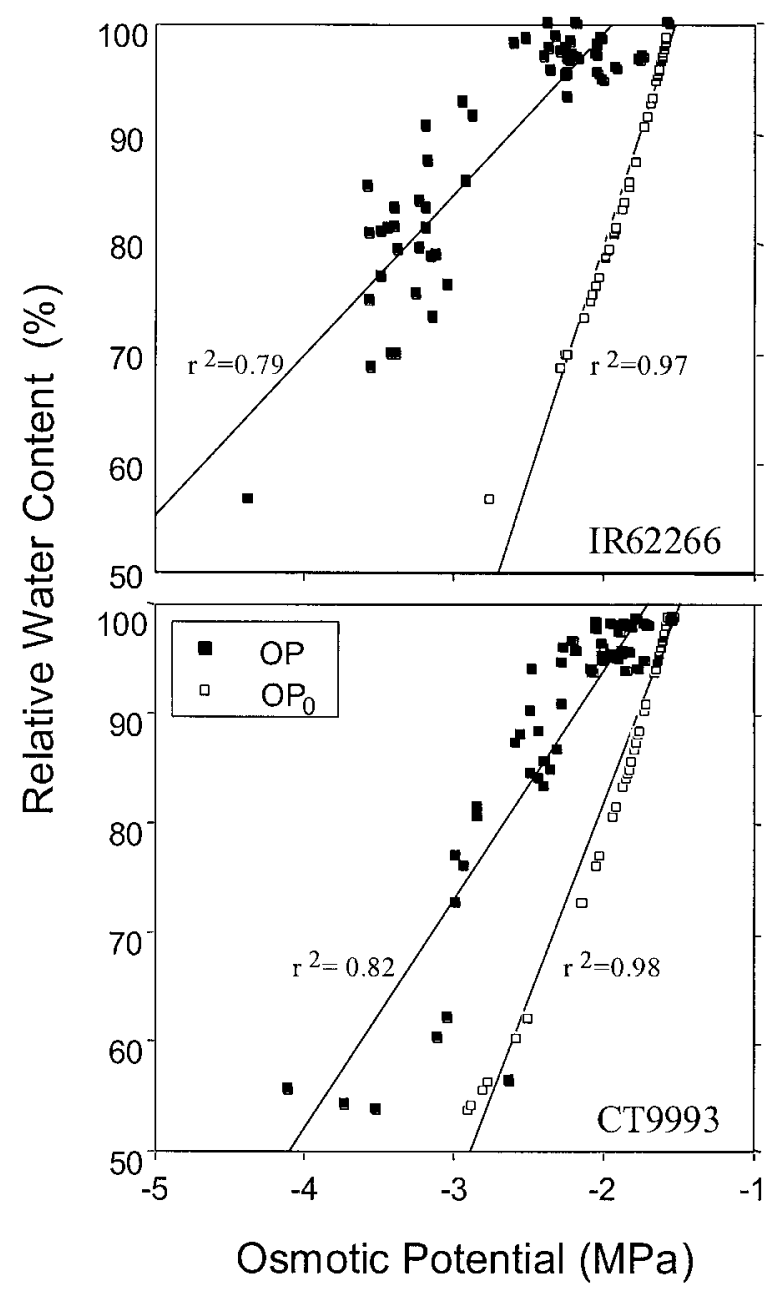

Fig. 2. The linear regressions of leaf relative water content (RWC) on osmotic potential (OP) under drought stress and on the calculated osmotic potential under the "concentration effect" $\left(\mathrm{OP}_{0}\right)$ in two rice cultivars of high (IR6226-42-6-2) and low (CT9993-5-10-1-M) osmotic adjustment (OA).
The $\mathrm{OP}_{0}$ was calculated for each RWC data point according to Morgan (1992) and Wright et al. (1983):

$$
\mathrm{OP}_{0}=\mathrm{OPi}[(\mathrm{RWCi} / 100) /(\mathrm{RWC} / 100)]
$$

where OPi is the initial OP in well-watered plants and RWCi is the initial RWC in well-watered plants.

Osmotic adjustment was calculated from the two regressions as the difference between $\mathrm{OP}$ and $\mathrm{OP}_{0}$ at RWC of $70 \%$. This RWC was chosen and rather than $60 \%$ (see below) because actual data were not always available to $60 \%$, and an extrapolation was deemed undesirable. While Morgan (1992) used natural $\log$ conversions of RWC and OP to improve the linearity of the relationship, such conversions were not deemed necessary here since they did not result in any improvement over using the unconverted data.

Method 2. By this method, OA was calculated as the difference in OP between nonstressed (a point measurement on the morning after last irrigation) and stressed leaves both calculated to well-watered state $\left(\mathrm{OP}_{100}\right)$ (Wilson et al., 1979; Flower and Ludlow, 1986; Ludlow et al., 1983; 1990). Data for the stressed plants consisted of those taken at a RWC of around $60 \%$ with a LWP of about $-3.5 \mathrm{MPa}$. This RWC was chosen to assure sampling at wilting in all cultivars. The $\mathrm{OP}_{100}$ was calculated as follows:

$$
\mathrm{OP}_{100}=\mathrm{OP}[(\mathrm{RWC}-B) /(100-B)] .
$$

A $B$ value of $18 \%$ was chosen for these calculations, as based on data for rice by Turner et al. (1986). A constant value of $B$ was used for both stressed and nonstressed leaves of all cultivars since $B$ did not change with cultivar (Turner et al., 1986) or dehydration (Wilson et al., 1980). A constant value of $B$ has also been used by others (e.g., Ludlow et al., 1983, 1990).

Method 3. By this method, OA was calculated as the difference in measured OP between nonstressed $(\mathrm{OPi}$, as measured above) and stressed leaves that are rehydrated (Jones and Turner, 1978; Wilson et al., 1980; Turner et al., 1986; Blum, 1989). Stressed plants at RWC of about $60 \%$ were irrigated in the evening and leaves were sampled the next morning for measurement of OP. According to Steponkus et al. (1982), overnight rehydration in itself was not expected to generate any significant variation among cultivars in OP after dehydration.

Method 4. The capacity for OA was estimated according to Morgan (1995) as the RWC at a given OP close to wilting $(-3.5 \mathrm{MPa})$. Higher RWC at a given OP indicates a relatively higher OA. This estimate was derived from the regression of RWC on OP used in Method 1 (solid squares, Fig. 2).

\section{Plant Response Evaluations (Experiment 2)}

The associations between OA, leaf death at peak drought stress and plant recovery after drought stress were assessed for eight rice cultivars in Exp. 2.

Osmotic adjustment was measured by Methods 1 and 3 on the 22nd day after the last irrigation when plants were at a RWC of 55 to $65 \%$ and a LWP of around $-3.5 \mathrm{MPa}$. These plants were scored for leaf death on a scale of 1 (all leaves green but rolled) to 9 (all leaves appear desiccated and dead) (De Datta et al., 1988). Pots that were irrigated on the 23rd day after the last irrigation (for OA determination by Method 3 ) were scored for plant recovery on the 24th day. Recovery scores were given as percentage of plants regaining turgor out of the eighteen irrigated plants per cultivar. Plant recovery scores were based on the Standard Evaluation System (SES) for rice (IRRI, 1980). 


\section{RESULTS \\ Experiment 1}

The duration of the period from the last irrigation to wilting, during which leaves were sampled for OA, ranged from 31 to $39 \mathrm{~d}$ depending on cultivar. For instance, cultivars IR58821-23-B-1-2-1, Azucena, and Moroberekan wilted completely at 31 d, while IR6391938-B-1 wilted at 39 days after last irrigation. Except for KDML-105 that had initiated heading, all cultivars were in the vegetative stage during the entire drought stress cycle.

The RWCi and OPi data taken in the morning after the last irrigation represented a well-watered state with no history of water deficit (Table 1). Cultivars ranged in RWCi from 95.5 to $99.8 \%$. This conforms to results of Morgan (1995) who did not observe a RWC of $100 \%$ in well-watered wheat plants. It also indicates that leaf samples measured for RWC were not over-hydrated during their incubation in water. Cultivars differed significantly $(P \leq 0.05)$ in $\mathrm{OPi}$, which ranged from -1.50 $\mathrm{MPa}$ in Moroberekan to $-2.02 \mathrm{MPa}$ in IR52561-UBN1-1-2. This was within the normal range reported earlier for rice (O'Toole, 1982) and wheat (Morgan, 1984). However, OPi did not correlate well with RWCi across cultivars $(r=-0.32 ; P=0.30)$. Hence, the variation among cultivars in OPi can be regarded as independent of RWCi and is, therefore, derived from constitutive differences among cultivars in cellular solute concentration.

\section{Osmotic Adjustment by Method 1}

Regressions of RWC on $\mathrm{OP}$ and $\mathrm{OP}_{0}$ for two different cultivars are presented in Fig. 2. The relationship between RWC and OP sometimes presents a bi-phasic response, as shown for chickpea (Morgan et al., 1991) or sunflower (Chimenti and Hall, 1993). In the first phase, OP is usually reduced with relatively little or no change in RWC. In the second phase there is a linear decline in both leaf RWC and leaf OP under the effect of water deficit. The two phases can be separated into two linear regressions by the proper statistical techniques; however, in this study, data for most cultivars and replications at high RWC (>95\%) were too scattered (e.g., Fig. 2) to allow the partitioning into two significant regressions per replication. Hence, the regression of RWC on OP (and the respective $\mathrm{OP}_{0}$ ) was fitted for all data as single-phase relationship, as done also by Morgan (1992) for wheat. All cultivars began to wilt at a RWC of $70 \%$ and data were available for all cultivars down to at least this RWC.

Cultivars differed significantly in OA more than fourfold, from $0.35 \mathrm{MPa}$ in IR52561-UBN-1-1-2 to $1.51 \mathrm{MPa}$ in IR62266-42-6-2 (Table 2). Coefficient of variation for this method was relatively high (47\%).

\section{Osmotic Adjustment by Method 2}

Mean OA across all cultivars by this method was 0.51 $\mathrm{MPa}$, compared with a mean of $0.89 \mathrm{MPa}$ by Method 1
Table 2. Osmotic adjustment as measured by three methods (1, 2 and 3) and the relative capacity for $\mathrm{OA}$ as estimated by RWC at $\mathrm{OP}$ of $-3.5 \mathrm{MPa}$ (Method 4) in 12 rice cultivars subjected to drought stress in Exp. 1.

\begin{tabular}{|c|c|c|c|c|}
\hline \multirow[b]{2}{*}{ Cultivar } & \multicolumn{3}{|c|}{ Osmotic adjustment } & \multirow{2}{*}{$\begin{array}{c}\text { RWC at }-3.5 \text { MPa } \\
(\text { Method 4) } \dagger\end{array}$} \\
\hline & \multicolumn{3}{|c|}{ Method $1 \uparrow$ Method 2 Method 3} & \\
\hline & & MPa & & $\%$ \\
\hline IR62266-42-6-2 & 1.51 & 0.83 & 1.01 & 77.3 \\
\hline IR42 & 1.19 & 0.59 & 1.07 & 80.9 \\
\hline IR63919-38-B-1 & 1.15 & 0.75 & 0.64 & 72.0 \\
\hline Lemont & 1.14 & 0.57 & 0.72 & 72.9 \\
\hline IR64 & 1.13 & 0.50 & 1.03 & 73.8 \\
\hline Teqing & 0.89 & 0.58 & 0.55 & 70.3 \\
\hline KDML-105 & 0.82 & 0.64 & 0.48 & 63.7 \\
\hline Azucena & 0.69 & 0.56 & 0.83 & 68.4 \\
\hline Moroberekan & 0.68 & 0.16 & 0.53 & 62.0 \\
\hline CT9993-5-10-1-M & 0.65 & 0.19 & 0.62 & 63.0 \\
\hline IR58821-23-B-1-2-1 & 0.52 & 0.23 & 0.69 & 62.3 \\
\hline IR52561-UBN-1-1-2 & 0.35 & 0.56 & 0.52 & 64.5 \\
\hline Mean & 0.89 & 0.51 & 0.72 & 69.3 \\
\hline CV\% & 47 & 32 & 21 & 24 \\
\hline LSD (0.05) & 0.29 & 0.25 & 0.18 & 3.1 \\
\hline
\end{tabular}

$\dagger$ Regression $r^{2}$ for RWC on OP ranged from 0.64 to 0.82 across cultivars.

(Table 2). The CV was $31 \%$, which was lower than with Method 1, but still high.

The relatively low OA values obtained with this method could not have been the result of insufficient level of drought stress. The OP values used here were obtained at a RWC of $\approx 60 \%$, which is lower than the value of $70 \%$ used in Method 1 . The reason for the relatively low $\mathrm{OA}$ values by this method are discussed below. Despite the relatively high $\mathrm{CV}$ and the low mean OA, very significant differences $(P \leq 0.01)$ were revealed in $\mathrm{OA}$ among cultivars, ranging from $0.16 \mathrm{MPa}$ in Azucena to $0.83 \mathrm{MPa}$ in IR62266-42-6-2 (Table 2).

\section{Osmotic Adjustment by Method 3}

Mean OA across all cultivars by this method was $0.72 \mathrm{MPa}$, compared with $0.89 \mathrm{MPa}$ and $0.51 \mathrm{MPa}$ for Methods 1 and 2, respectively. The CV (21\%) was the lowest of all methods (Table 2). The somewhat lower mean OA value obtained with this method compared with Method 1 could not be a result of insufficient level of drought stress. Possible explanations are discussed below. Very significant $(P \leq 0.01)$ and more than a twofold difference was observed in OA among cultivars, ranging from $0.48 \mathrm{MPa}$ in IR58821-23-B-1-2-1 to 1.07 $\mathrm{MPa}$ in IR42.

\section{Osmotic Adjustment by Method 4}

Mean RWC at OP of $-3.5 \mathrm{MPa}$ over cultivars was $69 \%$ (Table 2). This value was essentially the same as the RWC $(70 \%)$ at which OA was estimated by Method 1. The RWC at $-3.5 \mathrm{MPa}$ differed very significantly $(P \leq 0.01)$ among cultivars, from $80.9 \%$ (high OA capacity) in IR42 to $62 \%$ (low OA capacity) in Moroberekan. The CV was relatively low (24\%).

\section{Comparison of Methods}

Simple correlations of OA across cultivars between methods (Table 3, top values) indicated a significantly 
Table 3. Simple correlation coefficients (top number) and Spearman rank correlation coefficients (lower number) across 12 rice cultivars for osmotic adjustment as measured by four methods in Exp. 1.

\begin{tabular}{llcc}
\hline & Method 1 & Method 2 & Method 3 \\
\hline Method 2 & $0.54(0.07) \dagger$ & - & \\
& $0.54(0.07) \dagger$ & & - \\
Method 3 & $0.76(0.04)$ & $0.32(0.31)$ & \\
& $0.75(<0.01)$ & $0.16(0.61)$ & $0.80(<0.01)$ \\
Method 4 & $0.87(<0.01)$ & $0.67(0.02)$ & $0.73(<0.01)$ \\
& $0.83(<0.01)$ & $0.66(0.02)$ & \\
\hline
\end{tabular}

$\dagger$ Probability of significance.

better agreement of Method 3 than of Method 2 with Method 1. Results by Method 2 were not significantly correlated with those of Method 1. Results by Method 4 correlated well with those of Method 1, as would be expected, because both were derived from the same data sets. Results by Method 3 also correlated better than results by Method 2 with results by Method 4 . Results by Methods 2 and 3 were not correlated significantly. Spearman rank correlation analysis (Table 3, bottom values) basically confirmed the trend that emerged from the simple correlation analysis. The ranking of the twelve cultivars for OA by Method 1 agreed well with ranking by Method 4. Ranking by Method 1 agreed equally well with ranking by Methods 2 and 3 . Cultivar ranking by Methods 2 and 3 correlated poorly, while ranking by Method 4 agreed better with ranking by Method 3 than with ranking by Method 2. Ranking of cultivars for OA by Method 2 was, therefore, relatively odd, compared with the other methods.

The simple correlations $(r)$ calculated across 12 cultivars between OPi (Table 1) and OA (Table 2), as measured by the three methods, were low and nonsignificant $(P=0.13-0.88)$. Osmotic adjustment under drought stress appeared not to be related to the constitutive cellular solute concentration before the onset of stress.

\section{Experiment 2}

Plants grown in Exp. 2 were subjected to higher temperatures than those grown in Exp. 1 (Fig. 1). Mean initial RWC (RWCi) and mean initial OP (OPi) in well- watered plants before the onset of drying were $92.3 \%$ and $-1.93 \mathrm{MPa}$, respectively. Cultivars differed significantly for both RWCi and OPi.

Mean OA by Method 1 (Table 4) was only $0.18 \mathrm{MPa}$, compared with $0.89 \mathrm{MPa}$ by the same method in Exp. 1 . Osmotic adjustment by Method 1 ranged among cultivars, from $0.04 \mathrm{MPa}$ in IR52561-UBN-1-1-2 to $0.58 \mathrm{MPa}$ in IR63919-38-B-1. Differences between cultivars in OA were significant at $P \leq 0.05$, mainly because of cultivar IR63919-38-B-1, which also scored relatively high in Exp. 1. Mean OA by Method 3 was higher $(0.42 \mathrm{MPa})$ than that by Method 1, but it was still lower than the mean OA by this method in Exp. 1 (0.72 MPa). Cultivar differences in OA by Method 3 (Table 4) were not significant $(P=0.45)$.

As in Exp. 1, OA by either method was not correlated across cultivars with $\mathrm{OPi}$, indicating lack of association between $\mathrm{OA}$ and the different capacity of cultivars for constitutive solute accumulation. None of the results for OA as obtained here by the two methods correlated well across cultivars with OA values obtained by any of the three methods in Exp. 1, at least partly because of the lack of large or significant variation in OA among cultivars in Exp. 2. In general, therefore, the environmental conditions in Exp. 2 had a suppressing effect on $\mathrm{OA}$ and the expression of $\mathrm{OA}$ variation among cultivars, compared with Exp. 1.

Cultivars differed significantly $(P \leq 0.05)$ for leaf death score and recovery score (Table 4). Despite the relatively low cultivar variation for $\mathrm{OA}$ in this experiment, OA by Method 1 was negatively correlated with leaf death score $(r=-0.74 ; P=0.037)$ and positively correlated with recovery score $(r=0.77 ; P=0.024)$. No associations were seen between leaf death or plant recovery and OA by Method 3, probably because of the lack of significant variation among cultivars for $\mathrm{OA}$ by this method.

\section{DISCUSSION}

The rice cultivars tested here differed significantly for $\mathrm{OA}$ and therefore they were suitable materials for assessing the different methods of measurement. In Exp. 1,

Table 4. Initial relative water content $(\mathrm{RWCi})$ and initial osmotic potential $(\mathrm{OPi})$ as measured in well-watered plants before the onset of drying, osmotic adjustment as measured by two methods, leaf death score at peak stress and recovery score upon rehydration, in eight rice cultivars tested in Exp. 2.

\begin{tabular}{|c|c|c|c|c|c|c|}
\hline \multirow[b]{2}{*}{ Cultivar } & \multicolumn{2}{|c|}{ Well-watered } & \multicolumn{2}{|c|}{ Osmotic adjustment } & \multirow{2}{*}{$\begin{array}{l}\text { Leaf death } \dagger \\
\text { score }\end{array}$} & \multirow{2}{*}{$\begin{array}{c}\text { Recovery } \\
\text { score }\end{array}$} \\
\hline & RWCi & OPi & Method 1 & Method 3 & & \\
\hline & $\%$ & $\longrightarrow$ & MPa & - & & $\%$ \\
\hline Azucena & 91.3 & -1.95 & 0.10 & 0.36 & 5.1 & $\mathbf{0}$ \\
\hline CT9993-5-10-1-M & 95.1 & -1.80 & 0.08 & 0.40 & 5.6 & 0 \\
\hline IR52561-UBN-1-1-2 & 93.5 & -1.55 & 0.04 & 0.32 & 3.9 & 35.7 \\
\hline IR58821-23-B-1-2-1 & 92.9 & -1.53 & 0.11 & 0.47 & 5.2 & 35.7 \\
\hline IR61079-33-1-2-2-3§ & 89.9 & $-\mathbf{2 . 1 3}$ & 0.09 & 0.48 & 5.0 & 21.4 \\
\hline IR62266-42-6-2 & 94.6 & -2.38 & 0.23 & 0.54 & 3.8 & 22.2 \\
\hline IR63919-38-B-1 & 93.2 & -2.03 & 0.58 & 0.32 & 2.8 & 75.0 \\
\hline IR64 & 87.9 & -2.06 & 0.21 & 0.46 & 4.6 & 28.6 \\
\hline Mean & 92.3 & -1.93 & 0.18 & 0.42 & 4.5 & 27.3 \\
\hline LSD (0.05) & 2.1 & $\mathbf{0 . 3 0}$ & 0.21 & 0.24 & 0.09 & 19.3 \\
\hline
\end{tabular}

$\dagger \mathbf{1}=$ all leaves green but rolled; 9 = all leaves completely desiccated and dead.

$\$ 0=$ no plants recovered; $100=$ all plants recovered.

$\S$ Not tested in Exp. 1. 
OA by Method 1 differed between cultivars more than four-fold, ranging from $0.35 \mathrm{MPa}$ in IR52561-UBN-1-1-2 to $1.51 \mathrm{MPa}$ in IR62266-42-6-2. Such high values are comparable to the highest values observed in wheat (Morgan, 1992, 1995), barley (Hordeum vulgare L.) (Blum, 1989), and sorghum (Blum and Sullivan, 1986; Santamaria et al., 1990; Tangpremsri et al., 1995), and they are higher than those observed earlier in rice by Cutler et al. (1980), Hsiao et al. (1984), and Turner et al. (1986). This wide range of OA can be ascribed to the diversity of the genetic materials tested here, which is similar to more recent results of Lilley and Ludlow (1996).

Method 1 is regarded as the best estimate because of the extensive data it is based on and its account for the concentration effect on OP reduction under water stress (Morgan, 1992, 1995). Method 4 depends on the same data set collected for and analyzed by Method 1 . The difference between the two is that Method 4 does not account for possible variations among cultivars in the concentration effect on OP during a drought cycle. The high correlation across cultivars between these two methods as seen here would indicate that the variation among cultivars in concentration effect was not important for estimating cultivar differences in OA. This also seems to be the case in wheat, where Method 4 is used extensively by Morgan (Morgan, 1992, 1995). Use of Method 4 instead of Method 1 reduces the amount of calculations but not necessarily the amount of labor and plant material.

While Method 2 yielded significant differences in OA among cultivars, mean OA over cultivars was prominently lower by this method $(0.51 \mathrm{MPa})$ than by Methods $1(0.89 \mathrm{MPa})$ or $3(0.72 \mathrm{MPa})$. The relatively low OA values obtained with Method 2 could not have been the result of an insufficient level of drought stress because plants were stressed to about the same or lower RWC as with the other methods. The reason could perhaps lie in the assumptions on which the calculation is based. First, the correction for apoplastic water content ( $B=18 \%)$ could be unrealistic, despite its estimate for rice (Turner et al., 1986). However, an increase in calculated mean OA by this method to about the same mean value as obtained by Method 1 would require a $B$ value of around $40 \%$, which is unrealistically high. The $B$ estimates for other plant species (e.g., Boyer and Potter, 1973; Flower et al., 1990) were even lower than $18 \%$.

Second, the correction to a RWC of $100 \%$ may be unrealistic because normally grown well-watered plants never reach a RWC of $100 \%$, as pointed out by Morgan (1995). In our study, measured RWC of well-watered plants under normal growing conditions was also never $100 \%$ (Table 1). If calculations are made with RWC of $95 \%$ for well-watered plants, mean OA by Method 2 would decrease even further by $\approx 0.1 \mathrm{MPa}$. Therefore, these two corrections are not sufficient to explain the relatively low mean $\mathrm{OA}$ value by this method, unless $B$ for rice is set at $\approx 40 \%$ rather than $18 \%$. If $B$ for rice is indeed very high, then the probability of cultivar variations in $B$ may increase. These considerations pose a problem with Method 2.
Mean OA over cultivars by Method 3 was somewhat lower than that by Method 1 but not as low as for Method 2. A possible explanation could be that in Method 3, solutes were diluted by excessive apoplastic water during rehydration of the desiccated leaves. Furthermore, respiration during the rehydration period (overnight) may have reduced osmolality. However, Steponkus et al. (1982) presented data for OP after rehydration of stressed rice plants from which it appears that OA may have been stable for at least $24 \mathrm{~h}$ of rehydration. Still, this issue should be clarified in favor of a shorter rehydration period.

While Methods 1 and 4 are demanding in terms of labor and plant materials, Method 2 and 3 are more economical, faster, and appropriate for screening work. The correlations of OA across cultivars between methods indicated a better agreement of Method 3 than of Method 2 with Method 1 or 4 . Method 3 also had a smaller CV than Method 2. Thus, the results of this study support the use of Method 3 (the rehydration method) if a faster and a more economical alternative to Method 1 is required.

Several improvements may be considered when the rehydration method is used. First, rehydration of detached leaves or tillers (e.g., Hsiao et al., 1984) rather than of whole plants may be considered after some evaluation, which would conserve plant materials. Second, the measurement of OP by the psychrometric method as done here is slow. The freeze-thaw procedure for killing the tissue and its preparation for measurement, as well as the long equilibration time in the psychrometer chamber, may be a source of error. A faster and better method could be the measurement of expressed freeze-thawed leaf sap in an osmometer. While this method has also been debated (Kikuta and Richter, 1992), tissue sap extraction is possible with rehydrated tissues (Method 3), while it may not be possible with stressed tissue of low sap yield, such as with Method 2.

Any method for OA measurement should standardize or normalize for tissue water deficit. The OA estimates by Method 1 were performed at RWC of $70 \%$, and OA measurements by Methods 2 and 3 were performed at RWC of about $60 \%$. However, besides the tissue water deficit, time is a critical variable also. This is suggested from the poor development of OA in most instances in Exp. 2 compared with Exp. 1.

The rate of development of plant water deficit was faster in Exp. 2 than in Exp. 1, as judged by RWC (Fig. $3 \mathrm{~A}$ ). It took $\approx 20 \mathrm{~d}$ in Exp. 2 and $35 \mathrm{~d}$ in Exp. 1 to reach a mean RWC of $70 \%$. However, when the same data were evaluated on the basis of LWP (Fig. 3B), the rate of stress development was found to be about the same in the two experiments. The difference was that plants wilted at LWP of around $-2.5 \mathrm{MPa}$ in Exp. 2, while they wilted at LWP of about $-3.5 \mathrm{MPa}$ in Exp. 1. Temperature (Fig.1) and transpirational demand were higher in Exp. 2 than in Exp. 1. Evidence for the higher transpirational demand in Exp. 2 can be found in the mean (across the 7 common cultivars) RWCi in the two experiments, which was 98.6 and $92.6 \%$ in Exp. 1 and 

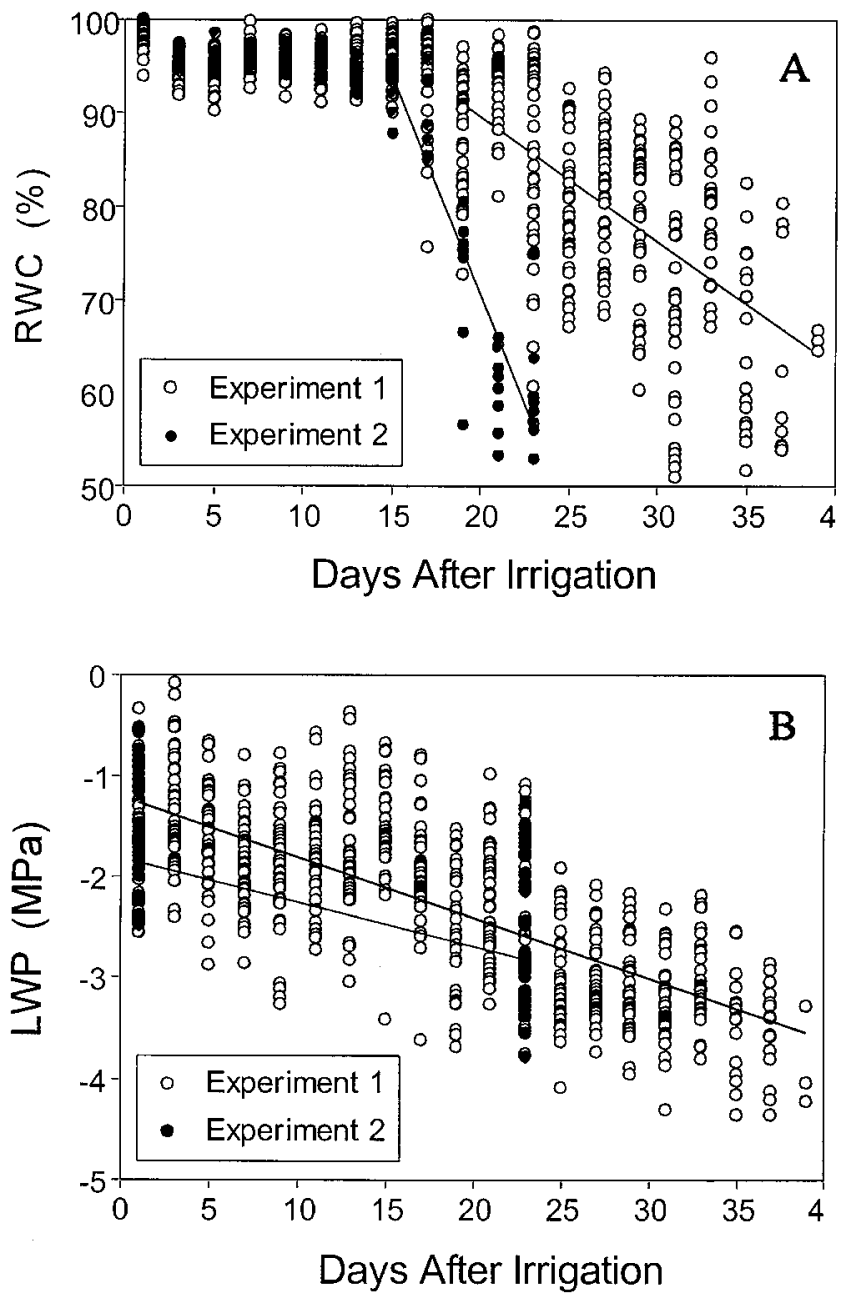

Fig. 3. The relationship between leaf relative water content (RWC) or leaf water potential (LWP) and time after the last irrigation, where regressions were fitted to the linear part of the relationship. (A) RWC: for Exp. 1, $y=116.5-1.34 x\left(r^{2}=0.38\right)$; for Exp. 2, $y=164.3-4.69 x\left(r^{2}=0.79\right)$. (B) LWP: Exp. 1, $y=-1.21-0.060 x$ $\left(r^{2}=0.52\right)$; Exp. 2, $y=-1.74-0.044 x\left(r^{2}=0.44\right)$. In Exp. 1, LWP data were available for all cultivars only on two dates.

2 , respectively. Plants were grown in the same soil volume in both experiments, but they reached wilting earlier in Exp. 2, not allowing enough time for solute accumulation and maintenance of high RWC. Jones and Rawson (1979) observed decreasing OA in containergrown sorghum plants when water deficit developed at a slow $\left(0.15 \mathrm{MPa} \mathrm{d}^{-1}\right)$, intermediate $\left(0.7 \mathrm{MPa} \mathrm{d}^{-1}\right)$, or fast $\left(1.2 \mathrm{MPa} \mathrm{d}^{-1}\right)$ rate of LWP reduction. In our study, the rate of LWP decline was the same in both experiments, if not slower in Exp. $2\left(-0.04 \mathrm{MPa} \mathrm{d}^{-1}\right)$ than in Exp. $1\left(-0.06 \mathrm{MPa} \mathrm{d}^{-1}\right)$ (Fig. 3B). Therefore, we hypothesize that it may not be the rate per se of stress development that is important for OA but the time available for solute accumulation before the plants wilt as a function of tissue water loss on one hand and the rate of solute accumulation on the other. This is a reasonable hypothesis if one considers that the rate of cellular solute accumulation has a limit and therefore full expression of OA capacity requires time. Our results indicate that rice requires about $4 \mathrm{wk}$ of drought stress to wilting for good expression of genetic variation in $\mathrm{OA}$, which seems to be more than is required by wheat
(Morgan, 1992) or sorghum (Jones and Rawson, 1979). The time required for OA may depend on the nature of the osmoticum and the rate of its accumulation, which could differ among different plant species.

Other possible reasons for the difference between experiments in mean OA should not be overlooked, such as a conceivable depressing effect of high temperatures on solute (sugars) accumulation in Exp. 2. However, mean OPi (OP of well-watered plants) over seven common cultivars, calculated from Tables 1 and 4, was lower in Exp. $2(-1.90 \mathrm{MPa})$ than that in Exp. $1(-1.76$ $\mathrm{MPa}$ ), indicating relatively greater solute accumulation in well-watered plants in Exp. 2 than in Exp. 1. A greater accumulation of solutes in well-watered plants of Exp. 2 would be supported by the fact that mean RWCi was also lower in Exp. 2 than in Exp. 1. Consequently, when $\mathrm{OA}$ is measured by the difference between $\mathrm{OP}$ and $\mathrm{OPi}$, it would be lower in plants of higher OPi, such as those in Exp. 2. It is difficult to quantitatively assess in this study the relative role of this effect and the effect of the duration of drying on OA. These results underscore the importance of the environment when screening for OA.

Constitutive accumulation of solutes can also be an effective component of turgor maintenance under drought stress, as seen in natural vegetation (Walter, 1965). In fact, constitutive accumulation (by overexpression of the responsible gene) of a cellular osmoticum is regarded as a serious approach to increasing crop drought resistance by genetic engineering (e.g., Bohnert et al., 1995). The OPi values obtained for the rice cultivars in the our study differed significantly in each of the two experiments. The OPi was independent of RWCi and it may therefore represent a long-term constitutive adaptive component, as argued by O'Toole (1982). This idea is also supported by the relatively greater constitutive solute accumulation observed in sorghum cv. M-35-1 (Shackel et al., 1982), one of the best dryland-adapted landraces in India; however, the constitutive accumulation of solutes may be totally unrelated to the capacity for $\mathrm{OA}$ in response to drought stress, as seen in this study by the lack of any significant correlation across cultivars between OPi and OA. Still, since OPi data are taken when OA is measured, it is recommended that differences in OPi should also be considered when selecting for OA.

Despite the relatively low variation among cultivars for OA in Exp. 2, OA by Method 1 was negatively correlated with leaf death score $(r=-0.74 ; P=0.037)$ and positively correlated with recovery score $(r=0.77$; $P=0.024)$. This may be taken as an indication that very small variations in OA can be effective in affecting these plant stress responses. Alternatively, the constitutive level of OA as represented by OPi could be associated with these plant responses to stress. However, OPi (Table 5) was not correlated with leaf death or with recovery.

In general, the results obtained here show that rice cultivars that are normally grown in lowland (wetland) conditions (Table 1) tend to express moderate to high OA capacity, with the exception of IR52561-UBN-1-1-2, which is a lowland cultivar of low OA capacity. On the other hand, traditional upland cultivars, such as Azu- 
cena or Moroberekan, appear to lack in OA. A similar trend could be seen in the results of others (Steponkus et al., 1982; Turner et al., 1986). For example, Steponkus et al. (1982) observed low levels of OA and no significant differences in this respect among the four dryland rice cultivars tested. The reasons for the possible advantage in OA capacity of wetland over dryland cultivars are purely speculative. It is probable that dryland cultivars were inadvertently selected mainly for larger roots (e.g., Price et al., 1997) and the ability to explore deep soil moisture, a trait that would promote avoidance of plant dehydration under drought stress. Hence, no selection pressure was imposed toward the evolution of OA. Wetland cultivars, which have shallow roots and are subject to dehydration when exposed to short periods of drought stress, may have been subjected to an effective selection pressure for high OA capacity.

\section{ACKNOWLEDGMENTS}

We wish to thank Drs. John C. O’Toole of the Rockefeller Foundation for his suggestions during the experiments; S. Sarkarung, IRRI, Philippines, for supply of rice seeds; Jingxian Zhang for his critical comments and help during preparation of the manuscript; the Rockefeller Foundation for a postdoctoral fellowship awarded to R.C. Babu; and Mr. M.L. Ali for his assistance.

\section{REFERENCES}

Barrs, H.D., and P.E. Weatherley. 1962. A re-examination of the relative turgidity technique for estimating water deficits in leaves. Aust. J. Biol. Sci. 15:413-428.

Basnayake, J., M.M. Ludlow, M. Cooper, and R.G. Henzell. 1993. Genotypic variation of osmotic adjustment and desiccation tolerance in contrasting sorghum inbred lines. Field Crop Res. 35:51-62.

Blum, A., 1988. Plant breeding for stress environments. CRC Press, Boca Raton, FL.

Blum, A., 1989. Osmotic adjustment and growth of barley cultivars under drought stress. Crop Sci. 29:230-233.

Blum, A., and C.Y. Sullivan. 1986. The comparative drought resistance of landraces of sorghum and millet from dry and humid regions. Ann. Bot. (London) 57:835-846.

Blum, A., C.Y. Sullivan, and H.T. Nguyen. 1997. The effect of plant size on wheat response to agents of drought stress: II. Water deficit, heat and ABA. Aust. J. Plant Physiol. 24:43-48.

Bohnert, H.J., D.E. Nelson, and R.G. Jensen. 1995. Adaptations to environmental stresses. Plant Cell 7:1099-1111.

Boyer, J.S., and J.R. Potter. 1973. Chloroplast response to low leaf water potentials. I. Role of turgor. Plant Physiol. 51:989-992.

Brown, R.W., and D.M. Oosterhuis. 1992. Measuring plant and soil water potentials with thermocouple psychrometers: Some concerns. Agron. J. 84:78-86.

Chimenti, C.A., and A.J. Hall. 1993. Genetic variation and changes with ontogeny of osmotic adjustment in sunflower (Helianthus annuus L.). Euphytica 71:201-210.

Cutler, J.M., K.W. Shahan, and P.L. Steponkus. 1980. Dynamics of osmotic adjustment in rice. Crop Sci. 20:310-314.

De Datta, S.K., J.A. Malabuyoc, and E.L. Aragon. 1988. A field screening technique for evaluating rice germplasm for drought tolerance during the vegetative stage. Field Crop Res. 19:123-134

Flower, D.J., and M.M. Ludlow. 1986. Contribution of osmotic adjustment to the dehydration tolerance of water-stressed pigeonpea (Cajanus cajan (L.) millsp.) leaves. Plant Cell Environ. 9:33-40.

Flower, D.J., A. Usha Rani, and J.M. Peacock, 1990. Influence of osmotic adjustment on the growth, stomatal conductance and light interception of contrasting sorghum lines in a harsh environment. Aust. J. Plant Physiol. 17:91-105.

Hsiao, T.C., J.C. O’Toole, E.B. Yambao, and N.C. Turner. 1984 Influence of osmotic adjustment on leaf rolling and tissue death in rice (Oryza sativa L.). Plant Physiol. 75:338-341.

IRRI, 1980. Standard evaluation system for rice. IRRI, Los Baños, Philippines.
Jamaux, I., A. Steinmetz, and E. Belhassen. 1997. Looking for molecular and physiological markers of osmotic adjustment in sunflower. New Phytol. 137:117-127.

Jones, M.M., and H.M. Rawson. 1979. Influence of rate of development of leaf water deficits upon photosynthesis, leaf conductance, water use efficiency and osmotic potential in sorghum. Physiol. Plant. 45:103-111.

Jones, M.M., and N.C. Turner. 1978. Osmotic adjustment in leaves of sorghum in response to water deficits. Plant Physiol. 61:122-126.

Kikuta, S.B., and H. Richter. 1992. Leaf discs or press saps, A comparison of techniques for the determination of osmotic potentials in freeze thawed leaf material. J. Exp. Bot. 43:1039-1044.

Kramer, P.J., and J.S. Boyer. 1995. Water relations of plants and soils Academic Press, San Diego.

Lilley, J.M., and M.M. Ludlow. 1996. Expression of osmotic adjustment and dehydration tolerance in diverse rice lines. Field Crop Res. 48:185-197.

Ludlow, M.M., and R.C. Muchow. 1990. A critical evaluation of the traits for improving crop yields in water limited environments. Adv. Agron. 43:107-153.

Ludlow, M.M., A.C.P. Chu, R.J. Clements, and R.G. Kerslake. 1983. Adaptation of species of Centrosema to water stress. Aust. J. Plant Physiol. 10:119-130.

Ludlow, M.M., F.J. Santamaria, and S. Fukai. 1990. Contribution of osmotic adjustment to grain yield of Sorghum bicolor (L.) Moench under water-limited conditions. II. Post-anthesis water stress. Aust. J. Agric. Res. 41:67-78.

Morgan, J.M. 1977. Differences in osmoregulation between wheat cultivars. Nature (London) 270:234-235.

Morgan, J.M. 1984. Osmoregulation and water stress in higher plants Annu. Rev. Plant Physiol. 35:299-319.

Morgan, J.M. 1992. Osmotic components and properties associated with genotypic differences in osmoregulation in wheat. Aust. J. Plant Physiol. 19:67-76.

Morgan, J.M. 1995. Growth and yield of wheat lines with differing osmoregulative capacity at high soil water deficit in seasons of varying evaporative demand. Field Crop Res. 40:143-152.

Morgan, J.M., R.A. Hare, and R.A. Fletcher. 1986. Genetic variation in osmoregulation in bred and durum wheats and its relationship to grain yield in a range of field environments. Aust. J. Agric. Res. 37:449-457.

Morgan, J.M., B. Rodrigues-Maribona, and E.J. Knights, 1991. Adaptation to water deficit in chickpea breeding lines by osmoregulation, relationship to grain yields in the fields. Field Crops Res. 27:61-70.

O'Toole, J.C. 1982 Adaptation of rice to drought prone environments p. 195-213. Drought resistance in crops with emphasis on rice. IRRI, Los Baños, Philippines.

Paleg, L.G., G.R. Stewart, and R. Starr. 1985. The effect of compatible solutes on proteins. Plant Soil 89:83-94.

Price, A.H., A.D. Tomos, and D.S. Virk, 1997. Genetic dissection of root growth in rice (Oryza Sativa L.). 1. A hydroponic screen. Theor. Appl. Genet. 95:132-142.

Qian, Y.L., and J.D. Fry. 1997. Water relations and drought tolerance of four turfgrasses. J. Am. Soc. Hort. Sci. 122:129-133.

Rodriguez-Maribona, B., J.L. Tenorio, and L. Ayerve. 1992. Correlation between yield and osmotic adjustment of peas (Pisum sativum L.) under drought stress. Field Crop Res. 29:15-22.

Santamaria, J.M., M.M. Ludlow, and S. Fukai. 1990. Contribution of osmotic adjustment to grain yield in Sorghum bicolor (L.) under water-limited conditions. I. Water stress before anthesis. Aust. J. Agric. Res. 41:51-65.

Shackel, K.A., K.W. Foster, and A.E. Hall. 1982. Genotypic differences in leaf osmotic potential among grain sorghum cultivars grown under irrigation and drought. Crop Sci. 22:1121-1125.

Shen, B., R.G. Jensen, and H.J. Bohnert. 1997. Increased resistance to oxidative stress in transgenic plants by targeting mannitol biosynthesis to chloroplasts. Plant Physiol. 113:1177-1183.

Steponkus, P.L., K.W. Shahan, and J.M. Cutler. 1982. Osmotic adjustment in rice. p. 181-194. In Drought resistance in crops with emphasis on rice. IRRI, Los Baños, Philippines.

Tan, W.X., and T.J. Blake. 1997. Gas exchange and water relations responses to drought of fast- and slow growing black spruce families. Can. J. Bot. 75:1700-1706.

Tangpremsri, T., S. Fukai, and K.S. Fischer. 1995. Growth and yield of sorghum lines extracted from a population for differences in osmotic adjustment. Aust. J. Agric. Res. 46:61-74. 
Turner, N.C., and M.M. Jones. 1980. Turgor maintenance by osmotic adjustment, a review and evaluation. p. 87-103. In N.C. Turner and P.J. Kramer (ed.) Adaptation of plants to water and high temperature stress. Wiley-Interscience, New York.

Turner, N.C., J.C. O’Toole, R.T. Cruz, E.B. Yambao, S. Ahmad, O.S. Namuco, and M. Dingkuhn. 1986. Responses of seven diverse rice cultivars to water deficit. II. Osmotic adjustment, leaf elasticity, leaf extension, leaf death, stomatal conductance and photosynthesis. Field Crop Res. 13:273-286.

Walter, H. 1965. The water economy and hydrature of plants. Annu. Rev. Plant Physiol. 6:239-252.
Wilson, J.R., M.J. Fisher, E.D. Schulze, G.R. Dolby, and M.M. Ludlow. 1979. Comparison between pressure-volume and dew pointhygrometry techniques for determining the water relations characteristics of grass and legume leaves. Oecologia 41:77-88.

Wilson, J.R., M.M. Ludlow, M.J. Fisher, and E.D. Schulze. 1980. Adaptation to water stress of the leaf water relations of four tropical forage species. Aust. J. Plant Physiol. 7:207-220.

Wright, G.C., R.C.G. Smith, and J.M. Morgan. 1983. Differences between two grain sorghum cultivars in adaptation to drought stress. III. Physiological responses. Aust. J. Agric. Res. 34:637-65.

\title{
Winter Wheat Responses to Bird Cherry-Oat Aphids and Barley Yellow Dwarf Virus Infection
}

\author{
Walter E. Riedell,* Robert W. Kieckhefer, Scott D. Haley, Marie A. C. Langham, and Paul D. Evenson
}

\begin{abstract}
Grain yield loss caused by bird cherry-oat aphid (Rhopalosiphum padi $\mathrm{L}_{\text {.) }}$ infestation and barley yellow dwarf virus (BYDV) infection may result from direct damage to the winter wheat (Triticum aestivum L.) crop as well as from reduced crop tolerance to stress environments. This greenhouse study measured the effects of $R$. padi infestation, BYDV infection, or a combination of $R$. padi plus BYDV on plant height, date of anthesis, yield, and yield components of four winter wheat varieties ('Roughrider', 'Norstar', 'TAM 107', and 'Vona') in the absence of additional environmental stresses. Treatments were applied at the two-leaf growth stage. Early in the pre-vernalization growth period, $R$. padi treatment (alone or in combination with BYDV) reduced plant height to about 55 to $60 \%$ of the control plant height while BYDV treated plants were about $90 \%$ of control. During the post-vernalization growth period, plant heights attained about $90 \%$ of control in the $R$. padi treatment, to about $80 \%$ of control in the BYDV treatment and to about $70 \%$ of control in the $R$. padi+ BYDV treatment. Dates of anthesis were later in the $R$. padi+BYDV treatments than in the $R$. padi treatments for Norstar, Roughrider, and Vona but not for TAM 107. Individual kernel weights in the BYDV and $R$. padi+BYDV treatments were less than control or R. padi treatments for Norstar, TAM 107, and Vona but not for Roughrider. Control or $\boldsymbol{R}$. padi-treated plants had a greater number of fertile heads than plants given the BYDV or $R$. padi+BYDV treatments. Grain yield was strongly associated with kernel number per plant. The number of kernels per plant was reduced $19 \%$ by the $R$. padi treatment, $36 \%$ by the BYDV treatment, and $50 \%$ by the $R$. padi+BYDV treatment. Grain yield was reduced $21 \%$ by the $R$. padi treatment, $46 \%$ by the BYDV treatment, and $58 \%$ by the R. padi+BYDV treatment. With the exception of date of anthesis and individual kernel weight, there were no significant treatment by variety interactions for plant height, grain yield, and yield components. We conclude that $R$. padi infestation and BYDV infection caused significant yield reductions and that the varieties tested had little difference in their responses to these treatments in the absence of additional environmental stress.
\end{abstract}

W.E. Riedell, R.W. Kieckhefer, USDA-ARS, NPA, Northern Grain Insects Res. Lab., Brookings, SD 57006; S.D. Haley, M.A.C. Langham, P.D. Evenson, Plant Science Dep., South Dakota State Univ., Brookings, SD 57007. Research supported in part by a grant from the South Dakota Wheat Commission. Cooperative investigations of the USDAARS and South Dakota Agric. Exp. Stn., Brookings, SD. Journal Series no. 2982. Received 6 April 1998. *Corresponding author (wriedell@ngirl.ars.usda.gov).

Published in Crop Sci. 39:158-163 (1999).
$\mathrm{B}^{\mathrm{m}}$ RD CHERRY-OAT APHIDS are efficient vectors of barley yellow dwarf virus and commonly infest winter wheat in the northern Great Plains (Yount, 1985; Kieckhefer and Kantack, 1988). Fall $R$. padi infestation of winter wheat may occur at the seedling developmental stage immediately following planting through the tiller developmental stage before crop dormancy (Kieckhefer and Kantack, 1988). Aphid feeding on winter wheat before dormancy is known to cause substantial crop injury and yield loss (Burton, 1986; McPherson et al., 1986). The magnitude of crop injury caused by these pests depends on the extent of the infestation (Kieckhefer et al., 1995), its timing during the growing season (Kieckhefer and Gellner, 1988), the growth stage of the plant at infestation (Pike and Schaffner, 1985), and whether the aphids transmit BYDV to the crop (McPherson et al., 1986). Fall infestations of $R$. padi in winter wheat have been shown to reduce yield from 20 to $75 \%$ (Pike and Schaffner, 1985; Kieckhefer and Kantack, 1988) while fall infection with BYDV can reduce yield from 46 to 91\% (Palmer and Sill, 1966; Fitzgerald and Stoner, 1967; Carrigan et al., 1981).

The causes of winter wheat yield loss to $R$. padi and BYDV may consist of two related components. The first component could be direct physiological damage to the crop that results in reduced crop growth and grain yield even under growing season environments that present no additional stresses. The second component could be a reduction in crop tolerance to environmental stresses. Several authors have suggested that environmental stresses, such as water stress or severe winter conditions, interact with $R$. padi- or BYDV-damaged crops to substantially reduce grain yield (Endo and Brown, 1962; Fitzgerald and Stoner, 1967; Andrews and Paliwal, 1983, 1986; Kieckhefer and Gellner, 1992). Greater understanding of the specific roles played by these two components in causing winter wheat yield loss to $R$. padi and BYDV may aid breeders in developing tolerant varieties and may suggest new crop management techniques that ameliorate this yield loss.

The research reported here examined the impact of $R$. padi infestation and BYDV infection on shoot growth and yield components of four winter wheat varieties 